\title{
Defending Semantic Generalism
}

\section{Daniel Whiting}

The definitive version of this article is published in Analysis 67.4 October 2007

pp. 303-311 by Blackwell Publishing, and is available at www.blackwellsynergy.com.

\section{Introduction}

'Particularism' is a meta-ethical theory resulting from a holistic doctrine in the theory of reasons. According to Jonathan Dancy, the foremost contemporary proponent of particularism, 'a feature that is a reason in favour of an action in one case may be no reason at all in another, or even a reason against' (2004: 190). From this, Dancy claims, it follows that the "possibility of moral thought and judgement does not depend on the provision of a suitable supply of moral principles' (2004: 7). This doctrine is of significant interest and import in its own right, and accordingly is the subject of considerable critical attention. The concern of this paper, however, is not meta-ethics but semantics.

A widely-held and seemingly intuitive view in the philosophy of language is that the meaning of a linguistic expression is determined by a rule governing its employment. Call this view 'semantic generalism'. According to it, an expression possesses the meaning it does in virtue of being subject to a general principle specifying the correct use of that expression. Linguistic competence, on this account, requires practical mastery of such a principle. 
One might suspect that meta-ethical particularism clashes with semantic generalism not least because among the expressions purportedly meaningful in virtue of their being governed by a rule would be terms of ethical appraisal. Dancy is alert to this and, indeed, hopes to show that the view that normativity 'is not a matter of the application of rules [...] applies as much to linguistic meaning as to moral or other practical purport' (2004: 198). ${ }^{1}$ In short, Dancy propounds what one might call 'semantic particularism'.

In this paper, I do not intend to offer direct arguments against semantic particularism as such. ${ }^{2}$ Instead, I aim to show that Dancy offers us no reason to accept it, that the considerations he adduces do not count against the generalist view that linguistic competence requires grasp of a rule determining the correct use of an expression. ${ }^{3}$

\section{Compositionality}

Dancy begins by distinguishing two views on the relation between the meaning of a complex expression and the meanings of its parts:

\footnotetext{
${ }^{1}$ As should be clear from this quotation, Dancy does not deny that meaning is an intrinsically normative notion, but only that such normativity is to be explained in terms of linguistic rules. For the purposes of this paper, I shall take for granted the normativity thesis. For further discussion, see Whiting 2007.

${ }^{2}$ For a 'semantic' argument in support of the meta-ethical view that there must be moral principles, see Jackson, Pettit and Smith 2000; cp. Dancy 2004: 109-11. Presumably, if that argument is cogent, it could equally be employed to establish a semantic conclusion.

${ }^{3}$ Of course, several other philosophers, e.g. Davidson (2005), argue against the view that linguistic competence requires grasping rules for the use of expressions. Assessing such arguments is beyond the scope of this paper. Also, there are notorious problems concerning the very possibility of 'following a rule' for the use of a term, of the kind Kripke (1982) raises. However, these puzzles are not Dancy's concern, and so are not mine. For an overview, see Miller 1998 ch. 5.
} 
Weak compositionality

Strong compositionality the meaning of a complex expression is determined by the meanings of its parts (in that context) and how they are combined.

the meaning of a complex expression is determined by the meanings of its parts and how they are combined, and its parts would make the same contribution to any other complex in any other context.

Strong compositionality obviously entails weak, but not vice versa. Dancy accepts weak compositionality as trivial, but rejects strong on behalf of the particularist. In his view, 'one and the same term can make different [semantic] contributions in different contexts' (2004: 194).

This, as Dancy makes clear, challenges three prevalent views in the philosophy of language:

First, that our understanding of utterances and sentences is inferential [i.e. that one can infer the meaning of a whole from antecedent understanding of the meanings of its parts]. Second, that the normativity of language is a matter of its being governed by rules. Third, that the terms of ordinary language have invariant core meanings. (2004: 197)

The generalist picture challenged here is one according to which, in virtue of its use being governed by a rule, a term has an 'invariant core meaning', in virtue of which in turn it makes an invariant contribution to the meanings of complex expressions and to what might be said by their utterance. 
An immediate worry with the resultant, particularist picture is that it appears to follow that any given term is limitlessly ambiguous, that it changes its meaning on each occasion of use. Consequently, it seems hard to comprehend how any ordinary speaker could ever have understanding of such an indefinite variety of meanings of the kind surely required for competence with that term.

By way of response, and in place of strong compositionality, Dancy proposes the following, positive account of linguistic competence. What one must grasp, to understand a term, is the 'range of contributions' that it might make in different contexts; one must have practical 'command of the sorts of difference that the presence of the term can make to the semantic value of the context in which it can appropriately be found'. In addition, in the light of that understanding, one must, on a particular occasion of use, 'be able to tell, to a reasonable degree, which particular contribution the term is in fact making' on that occasion (2004: 194). ${ }^{4}$

\section{$3 \quad$ A rule by any other name}

I shall discuss below examples of the kind that Dancy offers in support of his claims, but first it is worth considering a response to his sketch of linguistic competence that immediately suggests itself. One might ask whether it contains anything that the proponent of semantic rules need deny. As quoted above, Dancy allows that, for each term, there is a 'range of contributions' it can make in a given context. And one might think that it is precisely semantic rules that fix, for each term, such a range. Perhaps one should concede that a rule does not alone determine just what contribution a term makes on a particular occasion of use, but one might insist nonetheless that it does

${ }^{4} \mathrm{Cf}$. 'To know the meaning of the term is to know the sorts of semantic contribution that the term can make to a large context, and to have a general understanding of what sorts of context are those in which it will make this or that sort of contribution.' (Dancy 2004: 196) 
determine the kind of contribution it can make (presumably by determining the kind of way in which it is to be used).

Of course, certain semantic generalists might be reluctant to admit this much, but that is irrelevant. Dancy's critique is supposed to apply quite generally, not to any particular version of the view that linguistic expressions have rule-governed uses.

It is not yet clear, then, to what extent Dancy is genuinely opposing semantic generalism. Indeed, he explicitly allows that one can talk of 'the meaning' of an expression 'in general' as 'the range of differences that it can make', that there 'is a sense $[\ldots]$ in which the term has the same meaning wherever it appears' (2004: 194). And if one accepts this, one could surely accept that there is a principle governing its use on those occasions. Surprisingly enough, Dancy concedes even this, granting, 'In one sense, indeed, there is nothing wrong with thinking of the meaning of a term as a rule for its use' (2004: 198).

From the above, it might appear that Dancy advocates semantic particularism only to immediately relinquish it. On closer inspection, however, it becomes clear that this is not so.

For Dancy, there is a respect in which an expression has an invariant significance, but only insofar as one can trace a certain trajectory (my term) in the use of that expression, and so there is a sense in which it is governed by a rule, i.e. insofar as there are applications of the term that can accord or fail to accord with that trajectory. Crucially, the relevant pattern is not one that might be captured by a general principle 
of the kind that particularism forgoes, since it is 'essentially inarticulable' (2004: 196; cf. 198).

What Dancy opposes, therefore, is a view of semantic rules as the sort of thing that might be fully expressed or finitely specified. Although there is a sense in which it is appropriate to talk of an expression's having 'a meaning' constituted by 'a rule for its employment', that rule is not a standard that could be formulated in a way that might be the content of propositional knowledge and thereby be the grounds of a person's competence with that expression.

Here, indeed, is a view that conflicts with semantic generalism. But what reason is there to accept it? I find two arguments in Dancy in support of this claim, which I shall consider in turn.

\section{$4 \quad$ Open-endedness}

First, Dancy claims that, though there is a range of contributions that a term might make to a larger whole (a sentence or utterance), that range is irreducibly 'openended'. This is due to the fact that it is essential to the terms we use that they can be projected to new and unforeseen contexts. We could not run a language in which we needed to invent a new term from every context which did not exactly match up to the defined limitations of the terms we have already in hand. (2004: 196)

Since there is no limit to the number of unforeseen contexts a speaker might project a term into, and since one cannot introduce new terms without limit, then one should not think of competence with a term as consisting merely in grasp of an established

\footnotetext{
${ }^{5}$ Dancy takes the lead here from Cavell (1979).
} 
rule of use. No such rule could determine how to apply an expression, and so what contribution that expression would make, in unanticipated circumstances.

The kind of case that is supposed to convince us of this is, I take it, the following. One might hope that, if any term has a standard meaning in virtue of being subject to a rule of use, 'bachelor' does. Presumably, the relevant rule would be:

(1) Use 'bachelor' as one uses 'unmarried adult male'. or, alternatively, if one prefers rules to be of word-world form:

(1*) Apply 'bachelor' only to unmarried adult men.

No doubt such a rule could guide one's use of 'bachelor' within a limited range of cases. Following Harman (1999: 140), however, one might consider what to say of a non-standard case, such as the Pope. The Pope is an unmarried adult male - one would apply 'unmarried adult male' to him - but one would and should not apply 'bachelor' to the Pope, or use that term when speaking of him. Since competent speakers are able to judge correctly whether 'bachelor' is to be projected into a circumstance with respect to which the rule above provides no suitable guidance, and since one would typically expect a competent speaker to be able to do so, grasp of meaning cannot be founded upon grasp of such a rule. More generally, it seems that whatever rule-formulation is offered for the use of a term, there will be possible circumstances in which one judges it correct to employ that term in a way not permitted within the confines laid down by the rule

Suppose we grant for the sake of argument that it really would strictly-speaking be incorrect to call the Pope a 'bachelor', and suppose we grant also that our decision not to apply 'bachelor' in sentences concerning the Pope does not amount to implicitly 
changing the rules to which 'bachelor' is subject, does one have to reject generalism? I do not think so - at least not yet. The particularist needs to give a reason to think that a counterexample of the above kind is not just a product of the way the specific example is set up, i.e. the particular rule-formulation offered. Nothing so far suggests that one could not arrive at a more inclusive, and so accurate, specification of a rule that provides for all eventualities (perhaps one requiring that 'bachelor' only be applied to eligible unmarried adult men). An argument is needed to demonstrate that in principle this could not be done, that no matter how much one packs into the rule, it would still not provide for all contexts. In the absence of these arguments, we have no reason to think that the standards for the use of 'bachelor' (or any other term) are limitlessly open-ended, and thereby inarticulable, and hence no reason to reject semantic generalism.

Of course, one sympathetic to Dancy might suggest that we have no positive reason to expect to be able to arrive at suitable rule-specifications of the kind required for each term in a language. But, while it is often hard to judge where the burden of proof lies, it is fair to say that semantic generalism appears to be the default position. Indeed, Dancy never denies its intuitiveness. Thus, the onus is on its opponent to undermine it.

\section{$5 \quad$ Endlessly whirling}

Considerations of the kind addressed in the previous section do not seem to me really to get to what Dancy sees as fundamentally problematic about semantic generalism. Dancy suggests that what his opponent fails to see, with respect to the use of a term, is 
that normative control over projections does not belong to the single term alone. What determines the rights and wrongs of using this term in that unusual case is at least partly the other features of the case - or the other terms it seems right to use in it.

The point here is not that above, namely that a semantic rule laying down conditions for correct use might not anticipate all circumstances, but rather that whether those conditions could be said to obtain is itself be a circumstantial matter. Hence, 'The whole thing whirls on endlessly, without any fixed points' (2004: 196-7).

By way of illustration, consider the following putative semantic rule: ${ }^{6}$

(2) Apply 'stool' only to items of furniture with no back support designed for sitting on.

Does this rule settle, for any object, whether 'stool' correctly applies to it? Well, it does fix the conditions under which 'stool' applies, namely when an object is an item of furniture with no back support designed for sitting on. However, as Dancy rightly points out, whether those conditions obtain - whether in turn one would or should apply 'item of furniture with no back support designed for sitting on' to an object will depend on other features of the context. Imagine, for example, that one is faced with a $\log$ by a campfire. Whether one judges it correct to apply 'stool' to it will depend on whether one considers an item 'furniture' if it is only to be used once, or whether one counts rolling a log into place with one's foot 'designing', which may in turn depend on how carefully the log was selected and moved. Nothing in the rule itself settles or could settle those matters. Thus, whether an expression properly applies - whether in calling a log a 'stool' one speaks truly - depends on features of a

\footnotetext{
${ }^{6}$ For illuminating discussion of the kind of examples to follow and its significance for the philosophy of language, see Travis 1997. As I read Travis, he does not deny that there are semantic rules, but rather holds that those rules underdetermine what might be said by the use of the expressions they govern.
} 
context whose obtaining in turn depends on features of a context, and so on 'endlessly'. It is because this will be the case for any supposed semantic rule for the use of a term that Dancy thinks no such rule could be finitely articulated. Thus, linguistic competence cannot depend on knowledge of such a rule and generalism is to be rejected.

Surely, however, all a semantic generalist need hold is that a rule determines which features of a situation call or allow for the application of an expression. She does not also demand that the rule settle whether those features may themselves be said to obtain (although other rules might in turn determine the conditions under which it would be correct to say that they do). In the present case, the generalist could maintain, the rule fully determines that if it is appropriate to apply 'item of furniture with no back support designed for sitting on' then it is correct to apply 'stool'. The fact that context (rather than the rule in question) determines whether the antecedent of that conditional obtains is entirely consonant with the idea that such a rule is in force and might be articulated.

Consider, as another illustration, the sentence, 'The room is tidy'. If uttered when stood in a teenager's bedroom, and given both the present and past states of the room, this sentence might express a truth. If uttered in a room visually indistinguishable but in an expensive hotel, the same words might express a falsehood. If one accepts that these possibilities are genuine - which for present purposes I shall - one must accept that 'tidy' does not make an invariant contribution to the contexts in which it appears on each occasion of its use. To this extent, Dancy is correct. But this is entirely 
compatible with there being a rule that determines the sort of contribution 'tidy' makes, say:

(3) Apply 'tidy' to something only if that something is neat, orderly and uncluttered.

Of course, whether one would say of something that it is neat, orderly and uncluttered - what counts on a certain occasion as according with the rule - will in turn depend on the circumstances. But the semantic generalist need only hold that a rule determines the kind of conditions under which an expression applies (and so what kind of contribution it might make); she need and surely would not also hold, excessively, that it determine the exact conditions under which those conditions actually obtain (and so precisely what contribution the term makes), and so on 'endlessly'. If one only asks of a semantic rule that it fulfil the more modest role, there is no reason to think that it must be inexpressible.

Again, certain semantic generalists might not accept this picture but, again, that is irrelevant. Dancy's critique is supposed to apply quite generally, not to any particular version of the view that linguistic expressions have rule-governed uses.

\section{Conclusion}

In this paper, I challenged the cogency of Dancy's arguments against generalism, which aim to demonstrate that linguistic competence cannot consist in grasp of rules for the use of expressions on the grounds that such rules would be inarticulable. One argument for their being inarticulable seems to be that no finitely specified rule could provide for all eventualities. But, I argued, we have yet to be offered a principled reason to accept this pessimistic view and, one might add, it is hard to imagine how 
one might establish it simply by appeal to examples of rules that lack the required comprehensive coverage. Another consideration in support of the inarticulation claim is that, supposing a semantic rule laid down what counts in all contexts as conditions of correct application, whether those conditions obtain would itself depend on context, and so on without limit. But, I argued, laying down under what conditions a certain form of behaviour counts as correct is just what one should expect of a rule; one should not also expect it in turn to provide guidance as to when those conditions are met. Thus, I conclude, Dancy provides no decisive reason to reject semantic generalism. Of course, there might be other reasons to do so, but this is not the occasion to examine them. ${ }^{7}$

In closing, note that it remains an open question to what extent semantic generalism is indeed in conflict with meta-ethical particularism, that is, whether accepting that the uses of expressions are governed by general rules forces one to accept the existence of ethical principles. It might be the case, and I suspect it is, that the kind of holism in the theory of reasons that the particularist draws attention to is the kind the semantic generalist need not deny. ${ }^{8}$

\footnotetext{
${ }^{7}$ Often the view that there are general ethical principles specifying how one is to behave in certain conditions is associated, by both proponents and detractors, with the view that those conditions could and should be specified in wholly non-evaluative terms (see Little 2000). But nothing in semantic generalism as such commits one to this. One might hold that there are general rules governing the use of evaluative and non-evaluative terms alike, in virtue of which those terms have the meanings they do, without also holding that the conditions of correct use those rules lay down be given in exclusively non-evaluative terms. Whatever is to be said for or against this, it is independent of the issue of whether there are such rules at all.

${ }^{8}$ In remarks on this paper, for which I am grateful, Dancy has suggested that his primary aim is to show that an alternative picture to semantic generalism is available, one that is independently attractive, rather than to prove that generalism is false or argue against it as such. Assessing his alternative has not been the principal focus of this paper, although it is part of the aim of $\S 3$ above to question whether it genuinely qualifies as an alternative.
} 


\section{Bibliography}

Cavell, S. 1979. The Claim of Reason. Oxford: Oxford University Press.

Dancy, J. 2004. Ethics without Principles. Oxford: Oxford University Press.

Davidson, D. 2005. Truth, Language, and History. Oxford: Oxford University Press.

Harman, G. 1999. Reasoning, Meaning and Mind. Oxford: Oxford University Press.

Jackson, F., Pettit, P. and Smith, M. 2000. Ethical particularism and patterns. In Moral Particularism, ed. B. Hooker and M. Little. Oxford: Oxford University Press.

Kripke, S. 1982. Wittgenstein on Rules and Private Language. Oxford: Blackwell.

Little, M. 2000. Moral generalities revisited. In Moral Particularism, ed. B. Hooker and M. Little. Oxford: Oxford University Press.

Miller, A. 1998. Philosophy of Language. London: UCL Press.

Travis, C. 1997. Pragmatics. In A Companion to the Philosophy of Language, ed. B. Hale and C. Wright. Oxford: Blackwell.

Whiting, D. 2007. The normativity of meaning defended. Analysis 67: 133-140. 